Gut, 1963, 4, 299

\title{
The course and prognosis of ulcerative colitis
}

\author{
FELICITY C. EDWARDS AND S. C. TRUELOVE \\ From the Nuffield Department of Clinical Medicine, \\ The Radcliffe Infirmary, Oxford
}

EDITORIAL SYNOPSIS The authors have produced a unique study of 624 patients with ulcerative colitis for they have achieved a $100 \%$ follow-up of all these patients admitted to the Radcliffe Infirmary or to the Churchill Hospital, Oxford, from 1938 to March 1962 inclusive or who attended as out-patients during the same period. They are therefore able to present a most important analysis of the natural history of ulcerative colitis as it occurs in the general population. Part I concerns the short-term prognosis in the initial attack, Part II the long-term prognosis; Part III discusses the complications of the disease, and Part IV the risk of carcinoma.

Ulcerative colitis continues to be a dangerous disease without completely satisfactory treatment. Knowledge of its aetiology is so limited that medical treatment has evolved solely by trial and error, and it is uncertain whether recent innovations in therapy have affected the long-term prognosis substantially. There is also controversy as to whether surgery, usually implying major procedures, should be employed extensively. Of the many complications of ulcerative colitis, cancer of the colon is known to be an appreciable risk after some years of the disease, but it is still not known whether this risk is so great that preventive colectomy is indicated.

Some of these issues were examined in a previous study of the patients with this disease seen at the Radcliffe Infirmary and Churchill Hospital, Oxford, during the 11-year period 1938-48 inclusive (RiceOxley and Truelove, 1950a and b). The present study, which extends the period of observation until 1962, can be regarded as a continuation of the earlier work.

\section{DATA}

The primary sources of data were the case notes of all the patients with ulcerative colitis (including haemorrhagic proctitis) who were admitted to the Radcliffe Infirmary or to the Churchill Hospital from 1938 to March 1962 inclusive or who attended as out-patients during the same period. In the interests of brevity, we shall refer to these two hospitals as the Radcliffe Infirmary; and this is reasonable because they are under the same management, have a single records system, and the senior medical staff is common to both.
The diagnosis of ulcerative colitis was considered acceptable for the present study if the symptoms were compatible, the illness was not apparently caused by pathogenic bacteria, and sigmoidoscopy or barium enema (usually both) supported the diagnosis; in a very few cases, the diagnosis was made at necropsy.

A total of 624 patients fulfilled the diagnostic criteria just mentioned. Of these, 238 were currently attending the hospital and 75 were known to be already dead. A follow-up study has been made of the remaining 311 patients, using a variety of approaches, and it has proved possible to obtain adequate follow-up information about all of them. The follow-up enquiries took place during the five-month period ending 31 March 1962; continuation data have since been obtained on the latest entrants to the study, so that there is a minimum of a one-year follow-up in every case. In brief, there is reliable and up-to-date information in respect of $100 \%$ of the patients, the period of observation varying from one to 24 years, according to when they first attended the hospital.

In order to determine as completely as possible the progress of the disease up to the end of the study or until death, we have obtained reports from all other hospitals to which the patients were admitted, and from family doctors and specialists, to supplement the original questionnaire sent to every patient not currently attending our own hospital. In the case of patients who have died we know the certified cause of death in every instance; and whenever a post-mortem examination was made, we have obtained the pathologist's report.

It would have been impossible to obtain such a 
complete picture of the course of this illness without the active assistance of a large number of individuals and institutions, both lay and medical, and it is a pleasure to acknowledge their help. We are also grateful to the physicians and surgeons of the Radcliffe Infirmary for allowing us to include their patients in this study so that it embraces the total experience of the hospital.
In order to analyse the extensive data at our disposal, we have transferred all the relevant clinical information obtained from the case histories and the follow-up on to punched cards for mechanical sorting. We shall now consider the results under four main headings: 1 Short-term prognosis, 2 long-term prognosis, 3 complications, and 4 carcinoma of the colon.

\section{Part 1 Short-term prognosis}

We shall consider here the immediate outcome of the attack of ulcerative colitis which first brought the patient to the Radcliffe Infirmary. When dealing with a disease which can pursue either an intermittent or continuous course over many years, which may never recur after the original attack, or which may terminate fatally in that attack, bias may be introduced for several reasons if all such cases are considered together, and much valuable information will remain hidden. We have therefore made an initial separation of the patients into two groups: those who were referred in their first attack of ulcerative colitis ('first attack group') and those who were referred because of a relapse of established disease ('relapse group'). For the purpose of this study, any patient who had had continuous symptoms for more than 12 months from the onset of the disease up to the time of referral was included in the relapse group. For the most part, the results of the analysis are presented separately for these two main groups.

\section{RESULTS}

Table I shows the composition of the series. It shows that there were approximately $50 \%$ more women than men, and this applies equally to the
TABLE I

COMPOSITION OF SERIES BY SEX,

AND BY WHETHER PATIENTS FIRST ATTENDED THE RADCLIFFE INFIRMARY IN FIRST ATTACK OR IN A RELAPSE OF ESTABLISHED DISEASE

\begin{tabular}{lcll} 
& Men & Women & Total \\
\hline First attacks & 94 & 156 & 250 \\
Relapses & 157 & 217 & 374 \\
Total & 251 & 373 & 624
\end{tabular}

first attack cases and to the cases first seen in a relapse of established disease. About $40 \%$ of the series consisted of patients seen in their first attack of the disease and this was true for both men and women.

AGE OF ONSET Table II shows a detailed breakdown of the whole series, separately by sex, for the age of onset. It shows that there were relatively few cases beginning in childhood, but from the age of 15 years upwards the cases became numerous and exactly $75 \%$ of the series began their illness between 15 and 49 years of age. A substantial number of the patients $(108$, or $17 \%$ ) were over the age of 50 when they first developed symptoms, and there were 12 patients $(2 \%)$ in whom the illness developed when they were over 70 years of age.

TABLE II

COMPOSITION OF THE SERIES BY AGE AT ONSET OF THE DISEASE

\begin{tabular}{|c|c|c|c|c|c|c|c|c|c|c|c|c|c|c|c|c|c|c|}
\hline \multirow{3}{*}{$\begin{array}{l}\text { Age at } \\
\text { Onset (yr.) }\end{array}$} & \multicolumn{6}{|c|}{ First Attacks } & \multicolumn{6}{|c|}{ Relapses } & \multicolumn{6}{|c|}{ Whole Series } \\
\hline & \multicolumn{2}{|c|}{ Men } & \multicolumn{2}{|c|}{ Women } & \multicolumn{2}{|c|}{ Total } & \multicolumn{2}{|c|}{ Men } & \multicolumn{2}{|c|}{ Women } & \multicolumn{2}{|c|}{ Total } & \multicolumn{2}{|l|}{ Men } & \multicolumn{2}{|c|}{ Women } & \multicolumn{2}{|c|}{ Total } \\
\hline & No. & $\%$ & No. & $\%$ & No. & $\%$ & No. & $\%$ & No. & $\%$ & No. & $\%$ & No. & $\%$ & No. & $\%$ & No. & $\%$ \\
\hline $\begin{array}{l}0-9 \\
10-19 \\
20-29 \\
30-39 \\
40-49 \\
50-59 \\
60-69 \\
70-79 \\
80-84 \\
\text { Unknown }\end{array}$ & $\begin{array}{r}1 \\
9 \\
14 \\
26 \\
20 \\
7 \\
14 \\
2 \\
1 \\
-\end{array}$ & $\begin{array}{r}1 \cdot 1 \\
9 \cdot 6 \\
14 \cdot 9 \\
27 \cdot 6 \\
21 \cdot 3 \\
7 \cdot 4 \\
14 \cdot 9 \\
2 \cdot 1 \\
1 \cdot 1 \\
-\end{array}$ & $\begin{array}{r}1 \\
14 \\
29 \\
42 \\
24 \\
20 \\
18 \\
6 \\
2 \\
-\end{array}$ & $\begin{array}{r}0.6 \\
9 \cdot 0 \\
18.6 \\
26.9 \\
15.4 \\
12.8 \\
11 \cdot 5 \\
3.9 \\
1.3 \\
-\end{array}$ & $\begin{array}{r}2 \\
23 \\
43 \\
68 \\
44 \\
27 \\
32 \\
8 \\
3 \\
-\end{array}$ & $\begin{array}{r}0 \cdot 8 \\
9 \cdot 2 \\
17 \cdot 2 \\
27 \cdot 2 \\
17 \cdot 6 \\
10 \cdot 8 \\
12 \cdot 8 \\
3 \cdot 2 \\
1 \cdot 2 \\
-\end{array}$ & $\begin{array}{r}8 \\
21 \\
54 \\
36 \\
27 \\
6 \\
4 \\
1 \\
- \\
-\end{array}$ & $\begin{array}{r}5 \cdot 1 \\
13 \cdot 4 \\
34 \cdot 4 \\
22 \cdot 9 \\
17 \cdot 2 \\
3 \cdot 8 \\
2 \cdot 6 \\
0 \cdot 6 \\
- \\
-\end{array}$ & $\begin{array}{r}6 \\
27 \\
69 \\
55 \\
28 \\
19 \\
8 \\
- \\
\overline{5}\end{array}$ & $\begin{array}{c}2 \cdot 8 \\
12 \cdot 4 \\
31 \cdot 8 \\
25 \cdot 3 \\
12 \cdot 9 \\
8 \cdot 8 \\
3 \cdot 7 \\
- \\
- \\
2 \cdot 3\end{array}$ & $\begin{array}{r}14 \\
48 \\
123 \\
91 \\
55 \\
25 \\
12 \\
1 \\
- \\
5\end{array}$ & $\begin{array}{r}3 \cdot 8 \\
12 \cdot 8 \\
32 \cdot 9 \\
24 \cdot 3 \\
14 \cdot 7 \\
6 \cdot 7 \\
3 \cdot 2 \\
0 \cdot 3 \\
- \\
1 \cdot 3\end{array}$ & $\begin{array}{r}9 \\
30 \\
68 \\
62 \\
47 \\
13 \\
18 \\
3 \\
1 \\
-\end{array}$ & $\begin{array}{r}3 \cdot 6 \\
11 \cdot 9 \\
27 \cdot 1 \\
24 \cdot 7 \\
18 \cdot 8 \\
5 \cdot 2 \\
7 \cdot 1 \\
1 \cdot 2 \\
0 \cdot 4 \\
-\end{array}$ & $\begin{array}{r}7 \\
41 \\
98 \\
97 \\
52 \\
39 \\
26 \\
6 \\
2 \\
5\end{array}$ & $\begin{array}{r}1.9 \\
11.0 \\
26.3 \\
26.0 \\
13.9 \\
10.5 \\
7.0 \\
1.6 \\
0.5 \\
1.3\end{array}$ & $\begin{array}{r}16 \\
71 \\
166 \\
159 \\
99 \\
.52 \\
44 \\
9 \\
3 \\
5\end{array}$ & $\begin{array}{r}2.6 \\
11.4 \\
26.6 \\
25.5 \\
15.9 \\
8.3 \\
7.0 \\
1.4 \\
0.5 \\
0.8\end{array}$ \\
\hline TOTAL & 94 & $100 \cdot 0$ & 156 & $100 \cdot 0$ & 250 & $100 \cdot 0$ & 157 & $100 \cdot 0$ & 217 & 100.0 & 374 & $100 \cdot 0$ & 251 & $100 \cdot 0$ & 373 & $100 \cdot 0$ & 624 & $100 \cdot 0$ \\
\hline
\end{tabular}


TABLE II (condensed)

\begin{tabular}{|c|c|c|c|c|}
\hline \multirow{2}{*}{$\begin{array}{l}\text { Age at Onset } \\
(y r .)\end{array}$} & \multicolumn{3}{|c|}{ Whole Series } & \multirow{2}{*}{$\begin{array}{l}\text { Statistical } \\
\text { Significance of } \\
\text { the Differences }\end{array}$} \\
\hline & Men & Women & Total & \\
\hline $\begin{array}{c}<15 \\
15-49 \\
50+\end{array}$ & $\begin{array}{r}24 \\
192 \\
35\end{array}$ & $\begin{array}{r}19 \\
276 \\
78\end{array}$ & $\begin{array}{r}43 \\
468 \\
113\end{array}$ & $\begin{array}{c}x^{2}=8.5 \\
n=2 \\
p<0.05\end{array}$ \\
\hline Total & 251 & 373 & 624 & \\
\hline
\end{tabular}

The age of onset shows interesting variations according to sex. Below the age of 15 there was no appreciable difference between the number of males and females, there actually being a small surplus of boys, but from 15 onwards there is a consistent surplus of women which becomes more pronounced after the menopause. These relationships are shown in the condensed version of Table II and the differences in the age distribution by sex is statistically significant.

DURATION OF DISEASE BEFORE REFERRAL Table III shows the duration of the disease before referral to the Radcliffe Infirmary. As far as first attacks are concerned, the majority were referred during the first six months. When the relapse group is considered, there was wide variation in the length of history, with many longstanding cases of more than 10 years' duration.

TABLE III

DURATION OF DISEASE AT TIME OF REFERRAL TO THE RADCLIFFE INFIRMARY

First Attacks

\begin{tabular}{|c|c|c|c|c|c|}
\hline Months & $\begin{array}{l}\text { No. of } \\
\text { Patients }\end{array}$ & $\%$ & Years & $\begin{array}{l}\text { No. of } \\
\text { Patients }\end{array}$ & $\%$ \\
\hline$<1$ & 49 & $19 \cdot 6$ & $\begin{array}{l}<1 \\
1-2\end{array}$ & $\begin{array}{l}39 \\
98\end{array}$ & $\begin{array}{l}10 \cdot 4 \\
26 \cdot 2\end{array}$ \\
\hline $\begin{array}{l}1-2 \\
3-5\end{array}$ & $\begin{array}{l}78 \\
68\end{array}$ & $\begin{array}{l}31 \cdot 2 \\
27 \cdot 2\end{array}$ & $\begin{array}{c}3-4 \\
5-9 \\
10-19\end{array}$ & $\begin{array}{l}57 \\
68 \\
74\end{array}$ & $\begin{array}{l}15 \cdot 2 \\
18 \cdot 2 \\
19 \cdot 8\end{array}$ \\
\hline $6-12$ & 55 & $22 \cdot 0$ & $\begin{array}{l}20+ \\
\text { U.K. }\end{array}$ & $\begin{array}{r}34 \\
4\end{array}$ & $\begin{array}{l}9 \cdot 1 \\
1 \cdot 1\end{array}$ \\
\hline Total & 250 & $100 \cdot 0$ & & 374 & $100 \cdot 0$ \\
\hline
\end{tabular}

INCREASING NUMBER OF REFERRALS Figure 1 shows the number of patients with ulcerative colitis referred to the Radcliffe Infirmary since 1938 by separate five-year periods. It shows a progressive increase in the numbers with the most marked rise during the final period. One cannot conclude from this figure that the incidence of the disease is increasing because many patients with ulcerative colitis are referred from outside the normal catchment area of the hospital, especially recently. For the purpose of the present study, it is important to note that the proportion of first attacks remained remarkably constant throughout, being approximately $40 \%$ of the total cases.

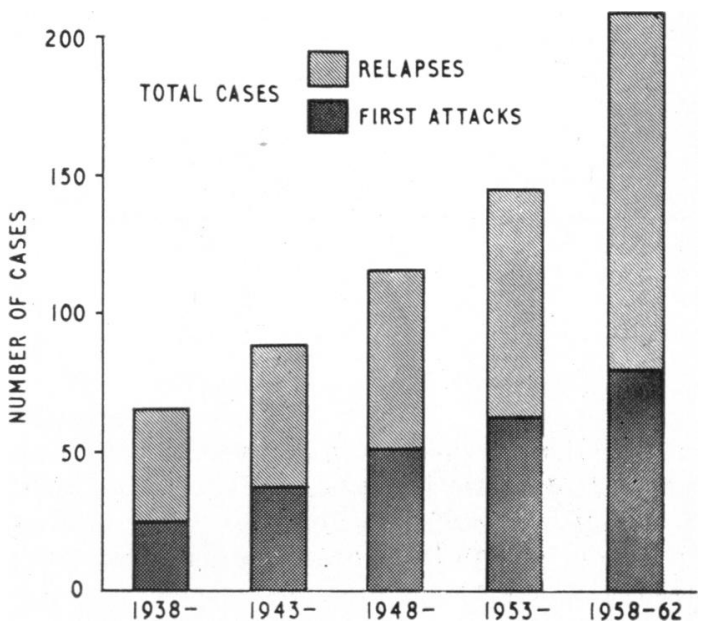

FIG. 1. The number of patients referred to the Radcliffe Infirmary in five-year periods.

\section{DEATH IN THE FIRST REFERRED ATTACK}

Table IV shows the proportion of patients in whom the attack of the disease for which the patient was first referred to the Radcliffe Infirmary terminated fatally. During the first decade covered by the study, first. attacks were decidedly more dangerous than relapses, but since 1948 this difference has disappeared. It can also be seen that there has been a progressive diminution in the proportion of fatal cases, the most marked change occurring in 1953, since when the fatality rate has been approximately steady. Such an improvement in short-term prognosis could be the result of various factors, the two most obvious possibilities being changes in treatment and changes in the severity of the disease at the time the patient reached hospital.

SEVERITY OF THE ATTACK The clinical severity of the attack has a profound influence upon short-term prognosis. We have classified each first referred attack into three grades of severity, employing the same criteria as were used in a large-scale therapeutic trial (Truelove and Witts, 1955), namely:-

Severe Severe diarrhoea (six or more motions a

TABLE IV

PERCENTAGE OF PATIENTS DYING IN FIRST REFERRED ATTACK, ACCORDING TO PERIOD OF REFERRAL

\begin{tabular}{lccc} 
& First Attacks & Relapses & All Cases \\
\hline $1938-42$ & $21 \cdot 7$ & $12 \cdot 2$ & $17 \cdot 2$ \\
$1943-47$ & $22 \cdot 2$ & $9 \cdot 6$ & $14 \cdot 8$ \\
$1948-52$ & $12 \cdot 1$ & $11 \cdot 9$ & $12 \cdot 1$ \\
$1953-57$ & $1 \cdot 6$ & $6 \cdot 0$ & $4 \cdot 1$ \\
$1958-$ & & & \\
March 1962 & $6 \cdot 3$ & $3 \cdot 8$ & $4 \cdot 8$
\end{tabular}


TABLE V

RELATIONSHIP BETWEEN CLINICAL SEVERITY OF FIRST REFERRED ATTACK AND DEATH IN THAT ATTACK SHOWN SEPARATELY FOR FIRST ATTACKS AND RELAPSES

\begin{tabular}{|c|c|c|c|c|c|c|}
\hline \multirow[t]{2}{*}{ Clinical Severity } & \multicolumn{2}{|c|}{ First Attacks } & \multicolumn{2}{|l|}{ Relapses } & \multicolumn{2}{|l|}{ All Cases } \\
\hline & $\begin{array}{l}\text { No. of } \\
\text { Patients }\end{array}$ & $\begin{array}{l}\% \\
\text { Died }\end{array}$ & $\begin{array}{l}\text { No. of } \\
\text { Patients }\end{array}$ & $\begin{array}{l}\% \\
\text { Died }\end{array}$ & $\begin{array}{l}\text { No. of } \\
\text { Patients }\end{array}$ & $\begin{array}{l}\% \\
\text { Died }\end{array}$ \\
\hline $\begin{array}{l}\text { Mild } \\
\text { Moderate } \\
\text { Severe }\end{array}$ & $\begin{array}{r}136 \\
67 \\
47\end{array}$ & $\begin{array}{r}0.7 \\
9.0 \\
38.3\end{array}$ & $\begin{array}{r}225 \\
82 \\
62\end{array}$ & $\begin{array}{r}0.9 \\
11.0 \\
25.8\end{array}$ & $\begin{array}{l}361 \\
149 \\
109\end{array}$ & $\begin{array}{r}0 \cdot 8 \\
10 \cdot 1 \\
31 \cdot 2\end{array}$ \\
\hline Total & 250 & $10 \cdot 0$ & 369 & $7 \cdot 3$ & $619^{1}$ & 8.4 \\
\hline
\end{tabular}

${ }^{1}$ Excluding three patients in complete remission on referral, and two for whom classification was not possible.

day) with macroscopic blood in stools; fever (mean evening temperature more than $99 \cdot 5^{\circ} \mathrm{F} .\left(37 \cdot 5^{\circ} \mathrm{C}\right.$.), or a temperature of $100^{\circ} \mathrm{F} .\left(37 \cdot 8^{\circ} \mathrm{C}\right.$.) or more on at least two days out of four; tachycardia (mean pulse rate more than 90 per minute); anaemia (haemoglobin $75 \%$ or less, allowance being made for recent transfusion); E.S.R. much raised (more than $30 \mathrm{~mm}$. in one hour).

Mild Mild diarrhoea (four or less motions a day) with no more than small amounts of macroscopic blood in stools. No fever. No tachycardia. Anaemia not severe. E.S.R. not raised above $30 \mathrm{~mm}$. in one hour.

Moderately severe Intermediate between severe and mild.

Table V and Fig. 2 demonstrate the close relationship between clinical severity at the time the patient reaches hospital and the risk of dying in that attack. For the whole series, mild attacks carried a very low risk of death, whereas severe attacks carried a grave short-term prognosis with nearly one-third dying.

Table VI shows that severe attacks have become a smaller proportion of the total referrals throughout the period of study, being counterbalanced by a progressive increase in the proportion of mild

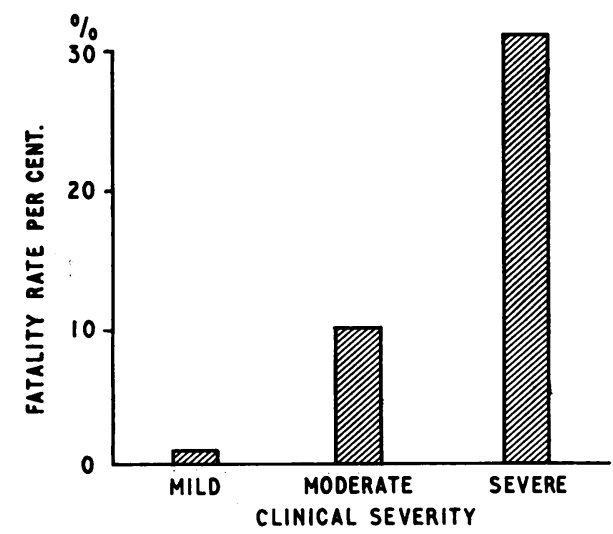

FIG. 2. Percentage fatality rate in the first referred attack in relation to the clinical severity of that attack.
TABLE VI

RELATIVE FREQUENCY OF SEVERE, MODERATE, AND MILD ATTACKS ON REFERRAL TO THE RADCLIFFE INFIRMARY ${ }^{1}$

\begin{tabular}{lcccc}
$\begin{array}{l}\text { Period of } \\
\text { Referral }\end{array}$ & $\begin{array}{l}\text { No. of } \\
\text { Patients }\end{array}$ & $\begin{array}{l}\text { Severe } \\
(\%)\end{array}$ & $\begin{array}{l}\text { Moderate } \\
(\%)\end{array}$ & $\begin{array}{l}\text { Mild } \\
(\%)\end{array}$ \\
\hline $1938-42$ & 64 & $20 \cdot 3$ & 35.9 & $43 \cdot 8$ \\
$1943-47$ & 88 & $30 \cdot 7$ & $21 \cdot 6$ & $47 \cdot 7$ \\
$1948-52$ & 116 & $24 \cdot 1$ & $20 \cdot 7$ & $55 \cdot 2$ \\
$1953-57$ & 146 & $13 \cdot 0$ & $24 \cdot 7$ & $62 \cdot 3$ \\
$1958-62$ & 205 & $10 \cdot 7$ & $22 \cdot 9$ & $66 \cdot 4$
\end{tabular}

CONDENSED VERSION OF THE ABOVE

$\begin{array}{lllll}1938-52 & 268 & 25 \cdot 4 & 24 \cdot 6 & 50 \cdot 0 \\ 1953-62 & 351 & 11 \cdot 7 & 23 \cdot 6 & 64 \cdot 7\end{array}$

${ }^{1}$ Whole series, but excluding the same five patients as in Table V.

attacks, while moderately severe attacks have remained a fairly steady proportion. It is evident from what has already been shown of the relationship between clinical severity of the attack and the short-term fatality rate that this shift in itself would be expected to improve the overall short-term prognosis in the second major period of the study. In order to see whether it can entirely account for the improved prognosis, the data must be analysed to take account simultaneously of severity of attack and time-period. This is done in Table VII and Fig. 3, which show a striking fall in the fatality rate of attacks of moderate severity, the change being highly significant statistically. Mild attacks carried a very low immediate risk of death in the earlier time-periods so no very great improvement could occur in terms of fatality. At the other end of the clinical scale, severe attacks have remained highly dangerous; a small improvement occurred in the second major time period, but it is not significant statistically.

It is plain that the improvement in the overall short-term fatality rate is partly due to a bigger proportion of patients being seen with mild attacks of the disease and partly due to a sharp decline in the fatality associated with attacks of moderate severity. This second factor can reasonably be attributed to improved methods of management. The medical 
TABLE VII

PERCENTAGE OF PATIENTS DYING IN FIRST REFERRED ATTACK ACCORDING TO THE CLINICAL SEVERITY OF THAT ATTACK ${ }^{1}$

Time Period

\begin{tabular}{l}
. \\
\hline $1938-52$ \\
$\begin{array}{l}\text { Statistical significance of the } \\
\text { differences }\end{array}$
\end{tabular}

\begin{tabular}{lll} 
Severe & & \\
\hline Total & No. & $\%$ \\
No. of & Died & Died \\
Patients & &
\end{tabular}

$\begin{array}{crrr}68 & 23 & 33.8 \\ 41 & 11 & 26.8 \\ & & \\ \chi^{2}=0.58 \quad \mathrm{n}=1 & \mathrm{p}>0.05 \\ \text { Not significant } & & \end{array}$

\begin{tabular}{lrr} 
Moderate & & \\
\hline $\begin{array}{l}\text { Total } \\
\text { No. of } \\
\text { Patients }\end{array}$ & $\begin{array}{l}\text { No. } \\
\text { Died }\end{array}$ & $\begin{array}{l}\text { \% } \\
\text { Died }\end{array}$ \\
\multicolumn{1}{l}{66} & 13 & $19 \cdot 7$ \\
83 & 2 & $2 \cdot 4$ \\
$x^{2}=12 \cdot 1 \quad \mathrm{n}=1$ & $\mathrm{p}<0.01$ \\
Highly significant & &
\end{tabular}

\begin{tabular}{lll} 
Mild & & \\
\hline $\begin{array}{l}\text { Total } \\
\text { No. of } \\
\text { Patients }\end{array}$ & $\begin{array}{l}\text { No. } \\
\text { Died }\end{array}$ & $\begin{array}{l}\% \\
\text { Died }\end{array}$ \\
\hline 134 & & \\
227 & 2 & 1.5 \\
& 1 & 0.4
\end{tabular}

Obviously not significant

'Whole series, but excluding the same five patients as in Table V.

management of an attack of ulcerative colitis consists of general medical measures and certain specific measures. The general medical measures consist essentially of steps designed to counteract the harmful effects of the disease, such as blood transfusion to replace blood lost through the bowel, parenteral therapy to overcome dehydration and electrolyte deficiencies, and a high-calorie, highprotein diet with added vitamins to preserve the state of nutrition. These general measures have not altered in principle during the period under study but technical advances have facilitated their application; for example, the development of flame photometry has improved control of electrolyte therapy and the
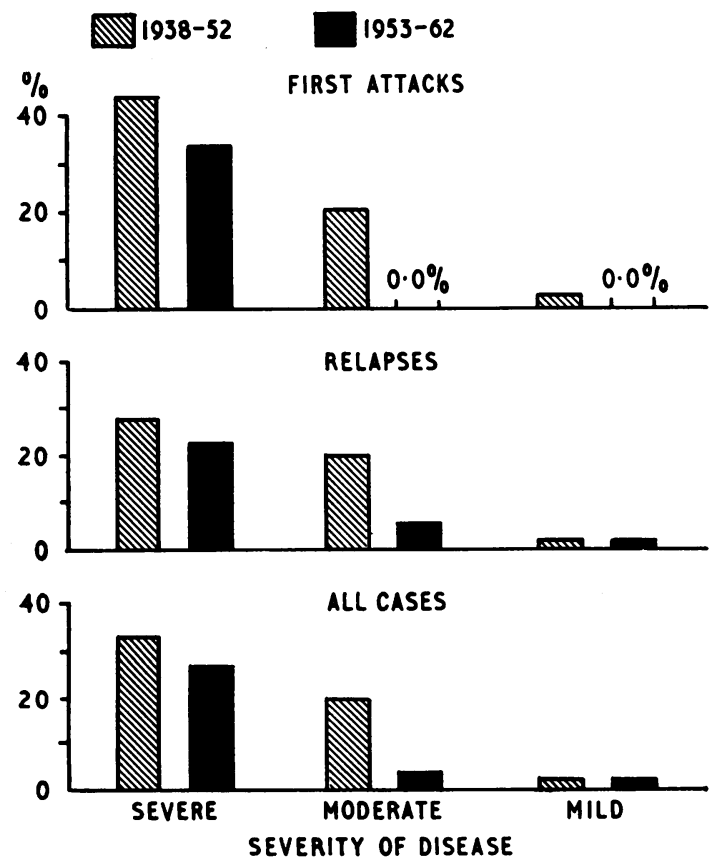

FIG. 3. Percentage fatality rate in the first referred attack, separately for first attacks and relapses, in relation to (a) severity of the disease, (b) treatment period. introduction of the National Blood Transfusion Service has made blood transfusion an easy and safe form of treatment. The major change in specific medical treatment has been the introduction of corticosteroid therapy, which began to be used in this hospital in 1952. In effect, when we deal with our two major time-periods, 1938-52 and 1953-62, we are concerned with the pre-cortisone eras.

Since 1952, corticosteroids have been increasingly used, but the exact type of treatment has varied. Apart from cortisone itself, A.C.T.H. was used for a time but has now been almost completely superseded by the modern synthetic analogues of cortisone, such as prednisolone. The systemic use of corticosteroids has been supplemented by local corticosteroid therapy applied by rectal drip since 1955 , although initially only a few patients were so treated. Although a series of controlled therapeutic trials has shown these measures to be beneficial in short-term treatment, their introduction into the routine clinical practice of the hospital inevitably lagged behind the formal studies and became the usual form of specific treatment only from about 1958. Any beneficial effects of corticosteroid treatment are therefore only partially shown in the present study.

The other specific therapy, sulphasalazine (Salazopyrin or Asulfidine) only became available in this country in 1955, although used in Sweden from 1940 onwards (Svartz, 1942). Sulphasalazine has not been used in a major way as specific therapy for ulcerative colitis in Oxford and has usually been employed in combination with corticosteroids. Its use is at present increasing.

In brief, although this type of retrospective study is obviously inferior to a controlled therapeutic trial for assessing the value of specific forms of treatment, it is nevertheless of interest that, since 1953, among the patients who died in their first referred attack of the disease about half had had no specific form of medical treatment (Table VIII).

Surgery has been employed in only a small 
TABLE VIII

PERCENTAGE OF PATIENTS DYING IN FIRST REFERRED ATTACK IN RELATION TO USE OF SPECIFIC MEDICAL TREATMENT FOR THAT ATTACK ${ }^{1}$

Specific Medical

Treatment (A.C.T.H.,

Corticosteroids,

Salazopyrin)

\begin{tabular}{ccc}
$\begin{array}{c}\text { Total Number of } \\
\text { Patients }^{2}\end{array}$ & $\begin{array}{l}\text { Number } \\
\text { Died }\end{array}$ & $\begin{array}{l}(\%) \\
\text { Died }\end{array}$ \\
\hline 102 & 7 & 6.9 \\
22 & 6 & 27.3
\end{tabular}

${ }^{1}$ Applies only to patients referred since 1953.

${ }^{2}$ Excluding mild attacks.

proportion of patients in their first referred attack throughout the entire period covered by the study (Table IX). Any improvement in short-term prognosis cannot be attributed to the more extensive use of surgery. Among those patients treated surgically, the fatality rate has fallen during the period covered by this study, a change which must partly reflect improved surgical technique.

OTHER FACTORS INFLUENCING THE CHANCE OF DYING IN THE FIRST REFERRED ATTACK A number of factors can be shown to have a bearing on the shortterm prognosis as far as death is concerned.

Sex of the patient Analysis of the data revealed no significant effect of sex on the short-term fatality rate (results not shown).

Age of the patient The age of the patient has a pronounced effect on the short-term fatality rate, which increases sharply in the older age groups, namely, at 60 years and over. This effect is consistent in first attacks and in relapses, and is statistically significant (Table X and Fig. 4). It is not due to older patients being more likely to present in a severe attack (Fig. 5).

There has been no appreciable proportionate increase of patients over the age of 60 in their first

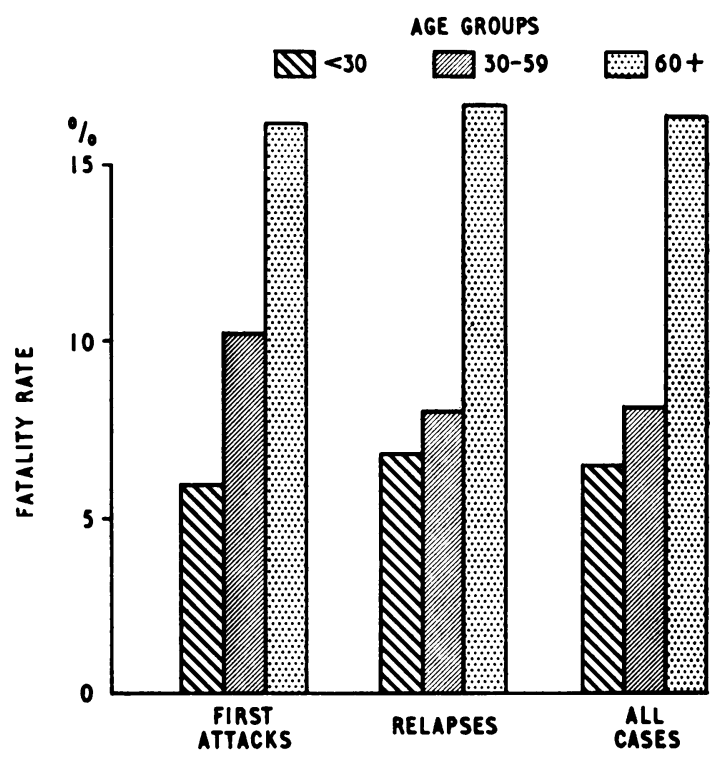

FIG. 4. The effect of age on the risk of dying in the first referred attack.

referred attack, and the improvement in fatality rate that occurred in the second main period of the study applied as much to them as to younger patients, the proportionate fall being almost identical (results not shown).

Type of onset The type of onset, whether acute or gradual, has little bearing on the short-term fatality rate (Table XI). We have confined ourselves to considering patients suffering from their first attack of ulcerative colitis, and we have excluded 29 patients in whom the information was not sufficiently precise to allow of classification.

Length of history As far as first attacks are

TABLE IX

PERCENTAGE OF PATIENTS TREATED BY ILEOSTOMY WITH OR WITHOUT COLECTOMY IN FIRST REFERRED ATTACK

\begin{tabular}{|c|c|c|c|c|c|c|}
\hline & \multicolumn{3}{|l|}{ First Attacks } & \multicolumn{3}{|l|}{ Relapses } \\
\hline & No. of Patients & No. Treated Surgically & $\%$ & No. of Patients & No. Treated Surgically & $\%$ \\
\hline $\begin{array}{l}\text { First period (1938-52) } \\
\text { Second period }(1953-62)\end{array}$ & $\begin{array}{l}108 \\
142\end{array}$ & $\begin{array}{l}7 \\
9\end{array}$ & $\begin{array}{l}6 \cdot 5 \\
6 \cdot 3\end{array}$ & $\begin{array}{l}160 \\
214\end{array}$ & $\begin{array}{l}14 \\
13\end{array}$ & $\begin{array}{l}8 \cdot 8 \\
6 \cdot 1\end{array}$ \\
\hline
\end{tabular}

TABLE X

EFFECT OF AGE ON DEATH IN THE FIRST REFERRED ATTACK

\begin{tabular}{|c|c|c|c|c|c|c|}
\hline \multirow[t]{2}{*}{ Age (yr.) } & \multicolumn{2}{|l|}{ First Attacks } & \multicolumn{2}{|l|}{ Relapses } & \multicolumn{2}{|l|}{ Whole Series } \\
\hline & No. of Patients & $\%$ Died & No. of Patients & $\%$ Died & No. of Patients & $\%$ Died \\
\hline $\begin{array}{l}<30 \\
30-59 \\
60+\end{array}$ & $\begin{array}{r}68 \\
139 \\
43\end{array}$ & $\begin{array}{r}5.9 \\
10 \cdot 1 \\
16.3\end{array}$ & $\begin{array}{r}102 \\
242 \\
30\end{array}$ & $\begin{array}{r}6.9 \\
7.0 \\
16.7\end{array}$ & $\begin{array}{r}170 \\
381 \\
73\end{array}$ & $\begin{array}{r}6.5 \\
8.1 \\
16.4\end{array}$ \\
\hline
\end{tabular}




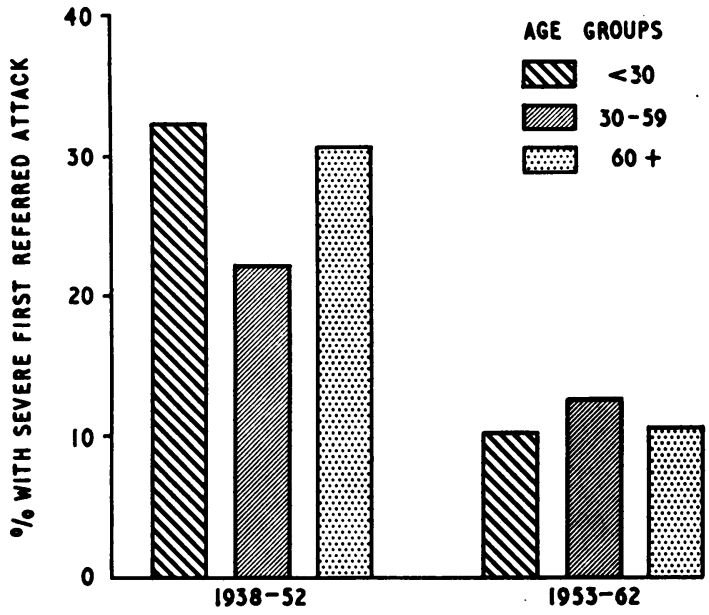

FIG. 5. Percentage of patients with a severe first referred attack, separately for three main age groups and for two treatment periods.

concerned, the shorter the history before referral to hospital, the worse the immediate prognosis (Table XII). This is probably no more than a reflection of the likelihood that early referral to hospital implies a severe attack of the disease.

Extent of the disease The extent of the disease, as judged by sigmoidoscopy, barium enema and, when

\section{TABLE XI}

DEATH IN FIRST ATTACK OF THE DISEASE, ACCORDING TO TYPE OF ONSET, ACUTE OR GRADUAL

\begin{tabular}{lcccl} 
Onset & $\begin{array}{l}\text { No. of } \\
\text { Patients }\end{array}$ & No. Died & $\%$ Died & $\begin{array}{l}\text { Difference } \\
\text { and S.E. }\end{array}$ \\
\hline Acute & 80 & 9 & $11 \cdot 3$ & $\begin{array}{l}3.5 \pm 4 \cdot 2 \\
\text { not } \\
\text { significant }\end{array}$ \\
Gradual & 141 & 11 & $7 \cdot 8$ &
\end{tabular}

relevant, the findings at surgery or necropsy, has an impressive effect upon the short-term fatality rate and this effect is consistent for first attacks and relapses (Table XIII). The results are based upon 502 patients for whom the information was precise and it excludes 22 patients because they suffered from
TABLE XII

DEATH IN FIRST ATTACK OF THE DISEASE ACCORDING
TO LENGTH OF HISTORY BEFORE ADMISSION TO HOSPITAL

\begin{tabular}{cccc}
$\begin{array}{c}\text { Duration } \\
\text { (months) }\end{array}$ & No. of Patients & No. Died & \% Died \\
\hline$<1$ & 49 & 9 & $18 \cdot 4$ \\
$1-5$ & 146 & 13 & 8.9 \\
$6-12$ & 55 & 3 & $5 \cdot 5$
\end{tabular}

Comparing less than one month's duration with remainder: $x^{2}=4 \cdot 74$, $\mathrm{n}=1, \mathrm{P}=<0.05$ significant.

right-sided or segmental colitis and 100 patients for whom the data were inadequate. It will be noted that first attacks of the disease are more dangerous than relapses even when the extent of the disease is taken into consideration. When patients are classified according to extent of the disease, as in Table XIII, it has been found that there has been little change in the proportions of the various categories during the period studied (results not shown).

RELATIONSHIP BETWEEN CLINICAL SEVERITY AND EXTENT OF THE DISEASE In view of the fact that the clinical severity of the first referred attack has a major influence on the short-term prognosis and that the extent of the disease likewise has a pronounced effect, we have examined the extent to which these factors are correlated. A considerable measure of correlation exists but the distribution is heavily skewed. A clinically severe attack almost always implies substantial or entire involvement of the colon; by contrast, involvement of the entire colon may be present when the attack of the disease is clinically mild, this being the case in about $20 \%$ of all the mild cases.

\section{CAUSES OF DEATH IN THE FIRST REFERRED ATTACK}

Death occurred in the first referred attack from a variety of causes (Table XIV). In some patients severe but uncomplicated ulcerative colitis proceeded to a fatal termination under medical treatment. Some

TABLE XIII

EFFECT OF EXTENT OF THE DISEASE ON DEATH IN FIRST REFERRED ATTACK

Extent of Disease
First Attacks

No. of
Patients

$\%$ Died

$0 \cdot 0$

$7 \cdot 3$

$25 \cdot 5$
Relapses

No. of
Patients

Distal type:

Rectum and rectosigmoid

Substantial involvement:

Descending \pm

Entire colon

$\begin{array}{rrrr}55 & 0.0 & 61 & 0.0 \\ 96 & 7.3 & 121 & 1.7 \\ 51 & 25.5 & 118 & 17.8\end{array}$


patients with severe uncomplicated ulcerative colitis died after emergency surgery. In other patients, particular complications of the disease were judged to be the immediate cause of death. In two patients death occurred from unrelated illnesses.

There has been a sharp reduction in the number of deaths from uncomplicated ulcerative colitis and this probably reflects improved medical treatment. It has already been shown (Table IX) that there was a small decline in the proportion of patients dealt with by emergency surgery. In effect, virtually the same number of patients was operated on in their first referred attack in each of the two main periods, although the total number of patients seen was much greater in the second period.

Deaths attributed to complications other than carcinoma of the colon also became less frequent. The complications of ulcerative colitis are diverse, but those chiefly liable to cause death in an attack of the disease are perforation of the colon and massive haemorrhage.

\section{OUTCOME OF THE FIRST REFERRED ATTACK}

If the patients did not die in the first referred attack, they usually became symptom-free in due course, although the period of time that elapsed before complete remission occurred was very variable.

The outcome of the first referred attack is given in Table XV. This deals with the entire series, with the exception of eight patients in whom the immediate course after they left hospital could not be ascer- tained, although the final outcome was discovered during the course of follow-up.

It is interesting to note that, since 1953, when corticosteroids began to be used, there has been an increase in the proportion of patients who go into complete remission (Table XVI). Of course, this table gives no information about the time taken to reach complete freedom from symptoms and it is known from controlled therapeutic trials that specific treatment with combined systemic and local corticosteroid therapy greatly increases the chance of rapid remission (Truelove, 1960; Truelove, Watkinson, and Draper, 1962). In other words, Table XVI almost certainly underestimates the reduction in morbidity which has occurred since 1953.

\section{DISCUSSION}

The present study has shown that ulcerative colitis

TABLE XVI

IMMEDIATE OUTCOME OF FIRST REFERRED ATTACK ACCORDING TO THE TWO MAIN TIME PERIODS

\begin{tabular}{|c|c|c|c|c|}
\hline \multirow[b]{2}{*}{ Outcome } & \multicolumn{2}{|l|}{$1938-52$} & \multicolumn{2}{|l|}{$1953-62$} \\
\hline & $\begin{array}{l}\text { No. of } \\
\text { Patients }\end{array}$ & $\%$ & $\begin{array}{l}\text { No. of } \\
\text { Patients }\end{array}$ & $\%$ \\
\hline $\begin{array}{l}\text { Died } \\
\text { Complete } \\
\text { remission } \\
\text { Improved } \\
\text { Unchanged } \\
\text { Colectomy } \\
\text { Total }\end{array}$ & $\begin{array}{r}38 \\
201 \\
19 \\
3 \\
1 \\
262\end{array}$ & \begin{tabular}{r|}
$14 \cdot 5$ \\
$76 \cdot 7$ \\
$7 \cdot 3$ \\
$1 \cdot 1$ \\
$0 \cdot 4$ \\
$100 \cdot 0$
\end{tabular} & $\begin{array}{r}16 \\
304 \\
29 \\
2 \\
3 \\
354\end{array}$ & $\begin{array}{r}4 \cdot 5 \\
85 \cdot 9 \\
8 \cdot 2 \\
0 \cdot 6 \\
0 \cdot 8 \\
100 \cdot 0\end{array}$ \\
\hline
\end{tabular}

${ }^{1}$ Excluding the eight patients in Table XV for whom the immediate outcome was unknown.

TABLE XIV

CAUSES OF DEATH IN FIRST REFERRED ATTACK

$\begin{array}{llll}\text { Time Period } & \begin{array}{l}\text { Uncomplicated Ulcerative } \\ \text { Colitis }\end{array} & \begin{array}{l}\text { Complications of } \\ \text { Ulcerative Colitis Other } \\ \text { than Carcinoma }\end{array} & \begin{array}{l}\text { Carcinoma Coli } \\ \text { Disease }\end{array}\end{array}$

1938-52

(268 patients)

1953-62

(356 patients)
14

3

10

4

1
10

5

TABLE XV

IMMEDIATE OUTCOME OF FIRST REFERRED ATTACK OF ULCERATIVE COLITIS (WHOLE PERIOD 1938-62)

\begin{tabular}{|c|c|c|c|c|c|c|}
\hline \multirow[t]{2}{*}{ Outcome } & \multicolumn{2}{|l|}{ First Attacks } & \multicolumn{2}{|l|}{ Relapses } & \multicolumn{2}{|l|}{ Whole Series } \\
\hline & No. of Patients & $\%$ & No. of Patients & $\%$ & No. of Patients & $\%$ \\
\hline $\begin{array}{l}\text { Died } \\
\text { Complete remission } \\
\text { Improved } \\
\text { Unchanged } \\
\text { Colectomy } \\
\text { Unknown }\end{array}$ & $\begin{array}{r}25 \\
209 \\
12 \\
2 \\
2 \\
-\end{array}$ & $\begin{array}{r}10 \cdot 0 \\
83 \cdot 6 \\
4 \cdot 8 \\
0 \cdot 8 \\
0 \cdot 8 \\
-\end{array}$ & $\begin{array}{r}29 \\
296 \\
36 \\
3 \\
2 \\
8\end{array}$ & $\begin{array}{r}7 \cdot 8 \\
79 \cdot 2 \\
9 \cdot 6 \\
0 \cdot 8 \\
0 \cdot 5 \\
2 \cdot 1\end{array}$ & $\begin{array}{r}54 \\
505 \\
48 \\
5 \\
4 \\
8\end{array}$ & $\begin{array}{r}8 \cdot 7 \\
80 \cdot 9 \\
7 \cdot 7 \\
0 \cdot 8 \\
0 \cdot 6 \\
1 \cdot 3\end{array}$ \\
\hline Total & 250 & 100.0 & 374 & 100.0 & 624 & $100 \cdot 0$ \\
\hline
\end{tabular}


remains a formidable disease even in the short term and ignoring the dangers which arise from its being a chronic disorder. Appreciable numbers of patients still die in the attack for which they are referred to hospital. The main factors which lead to a high risk of dying in this attack are a severe clinical picture at the time of referral, extensive disease especially when the whole colon is involved, and the development of a dangerous complication of which perforation of the colon is the chief example; the risk is considerably accentuated if the patient is over the age of 60 years.

In the previous study from this hospital, first attacks were found to be much more dangerous than relapses. In the present study there is not much to choose between them, but it must be emphasized that the earlier study took into consideration all relapses treated in the hospital whereas here we have been concerned only with the first referred attack. If we had included all relapses treated in hospital, we should again find a much lower fatality rate for relapses.

Overall, the short-term fatality rate has shown a considerable improvement during the last decade of the study. This is partly because of the lower proportion of patients severely ill at the time they reach hospital; it is not due to a lower proportion of patients with disease involving the whole colon, which is the same as previously; nor is it due to any decrease in the proportion of patients over 60 years of age at the time of the first referred attack. However, when allowance is made for the change in proportion of severe attacks, there is still evidence of considerable improvement since the introduction of cortisone treatment in 1952, but on analysis this is found to be almost entirely due to a marked improvement in the outcome of patients moderately ill on arrival at hospital. Those severely ill on arrival have shown only a small improvement and they remain as a challenge to the physician.

It must be appreciated that the results of a study such as this, which deals with the total experience of a hospital, are likely to lag behind the changes occurring in specialized units. For example, when cortisone began to be used in this hospital in 1952, it was employed only in the patients admitted to a formal therapeutic trial and even then only half the patients received the drug. It was not until 1954 that this trial was concluded and cortisone or A.C.T.H. began to be used more generally in the treatment of this disease. Local corticosteroid treatment began to be used in 1955 but was at first confined to selected mild or moderate cases (Truelove, 1956, 1957). When subsequent controlled trials had shown it to be beneficial in such cases (Truelove, 1958; Watkinson, 1958) it began to be used more extensively but its use in severe attacks of the disease did not begin until 1957. Subsequently the combined use of systemic and local corticosteroid treatment was found to. be advantageous (Truelove, 1960) and as a result this combined corticosteroid treatment has begun to enter general hospital practice. It is therefore plain that the results obtained for the period 1953-62 can be expected to show only a partial reflection of the benefits possible from corticosteroid therapy and a further study will be necessary to evaluate the full effect of this in the general hospital population of ulcerative colitis cases.

The question nevertheless arises whether a severe attack of the disease is not an indication for emergency colectomy. There are few physicians who would contemplate such a step as an immediate procedure in every patient admitted to hospital severely ill with ulcerative colitis. Some surgeons have advocated emergency colectomy in such patients if they do not show swift improvement with a full medical regime, but opinion is divided on how long to wait before resorting to colectomy. For example, Brooke (1956) considered that persistence with corticosteroid therapy in the absence of definite clinical improvement might lead to friability of the entire colon and so prejudice the results of emergency surgery. He concluded that 'steroid therapy should cease in any patient showing no response after one or two weeks', the implication being that they would then be treated by surgery. Lennard-Jones and Vivian (1960) discussed the experience of St. Mark's Hospital and the Central Middlesex Hospital in the management of fulminating ulcerative colitis, by which was implied a very severe attack; unfortunately they did not use a precise definition of a 'fulminating' attack but from their description of the cases, they appear to correspond roughly with our own 'severe' category. Among the 32 patients reviewed, 26 were brought to surgery, with eight deaths $(30.8 \%)$. The authors contrast this high operative fatality rate with the low rate after elective surgery in St. Mark's Hospital during the same period. Similarly Goligher (1961) has reported a low fatality rate for elective surgery but a high figure for emergency surgery. The close correspondence between these two surgical series can be seen when the operative fatality rates are tabulated:-

\begin{tabular}{llll} 
& $\begin{array}{c}\text { Elective } \\
\text { Surgery }\end{array}$ & $\begin{array}{l}\text { Emergency } \\
\text { Surgery }\end{array}$ \\
\hline Lennard-Jones and Vivian & & \\
Goligher (1961) (1960) & $4 \cdot 4 \%$ & $30 \cdot 8 \%$ \\
& & $2 \cdot 9 \%$ & $29 \cdot 3 \%$
\end{tabular}

The authors of both of these series conclude that, if corticosteroid treatment is employed in these 
severe attacks, its use should not be continued beyond a specified time limit if there is no sign of a major clinical improvement. Their view of the time limit differs, Lennard-Jones and Vivian taking four days as the period of medical trial, whereas Goligher takes 10 days. Their assumption is that emergency surgery would be less hazardous if performed earlier in the course of the illness than was usual in their cases. This view is strongly pressed by Gallagher, Goulston, Wyndham, and Morrow (1962) who claim that their overall results for severe ulcerative colitis have improved since they adopted the policy of early operation after a short period of intensive treatment usually lasting one to three weeks; among 22 patients so treated, there were only two deaths $(9 \cdot 1 \%)$.

It must be appreciated that these are all uncontrolled studies and the evidence in favour of early emergency colectomy is far from achieving the weight of scientific proof. The medical treatment of a severe attack of ulcerative colitis is attended by a considerable fatality rate, but emergency colectomy is also dangerous in a patient who is already seriously ill. There thus appears to be an incontrovertible case for a fully controlled therapeutic trial to compare, on the one hand, early emergency colectomy with, on the other hand, a full medical regime in which emergency colectomy is only practised when medical treatment is plainly failing or when there is some complication requiring urgent surgery, such as perforation of the colon.

\section{SUMMARY OF PART I}

A study has been made of the clinical course and prognosis in 624 patients treated for ulcerative colitis at the Radcliffe Infirmary between 1938 and 1962 and completely followed-up. In this part of the study we have confined ourselves almost entirely to considering death in the first referred attack.

The chief factors affecting the fatality rate in the first referred attack of the disease were as follows:-

SEVERITY OF THE ILLNESS AT TIME OF REFERRAL TO HOSPITAL Patients severely ill had a high chance of dying, patients moderately ill had a much lower but still appreciable risk, whereas patients only mildly ill had a negligible risk.

EXTENT OF THE DISEASE Universal colitis carried the highest risk, involvement of a substantial part of the colon a lower risk, whereas the distal type confined to the rectum and rectosigmoid carried virtually no risk to life.

AGE OF THE PATIENT Patients over the age of 60 had a much greater chance of dying than younger patients. This was not because they were more liable to suffer from severe attacks of the disease but because they did not survive such attacks as readily as the younger patients.

There has been a pronounced decline in the overall fatality rate since the introduction of corticosteroid therapy in 1952. This decline is not due to an increase in the employment of radical surgery in the acute attack, although there is evidence of a certain measure of improvement in the operative fatality rate. Part of the decline is due to a lower proportion of the patients being severely ill when reaching hospital in their first attack. When allowance is made for this fact, a substantial improvement can still be shown for the overall results. However, more detailed analysis shows that this improvement comes almost entirely from a sharp improvement in the outcome of the illness in patients moderately ill on arrival at hospital, while patients severely ill on arrival have shown only a small decline in fatality rate.

From the point of view of the short-term course, the finding that severe attacks of the disease continue to carry a considerable fatality rate brings out the main unanswered question of therapy at the present time. This is whether or not an emergency colectomy should be performed with minimal delay in patients who present with such severe attacks. The available published evidence bearing on this issue is briefly discussed and it is concluded that only a fully controlled therapeutic trial would permit of a proper answer.

\section{REFERENCES}

Brooke, B. N. (1956). Cortisone and ulcerative colitis: an adverse effect. Lancet, 2, 1175-1177.

Gallagher, N. D., Goulston, S. J. M., Wyndham, N., and Morrow, W. (1962). The management of fulminant ulcerative colitis. Gut, 3 , 306-311.

Goligher, J. C. (1961). Surgical treatment of ulcerative colitis. Brit. med. J., 1, 151-154.

Lennard-Jones, J. E., and Vivian, A. B. (1960). Fulminating ulcerative colitis: recent experience in management. Ibid., 2, 96-102.

Rice-Oxley, J. M., and Truelove, S. (1950a). Complications of ulcerative colitis. Lancet, 1, 607-611. $-\frac{1}{663-666}$.

Svartz, N. (1942). Salazopyrin, a new sulfanilamide preparation. Acta med. scand., 110, 577-598.

Truelove, S. C. (1956). Treatment of ulcerative colitis with local hydrocortisone. Brit. med. J., 2, 1267-1272.

(1957). Treatment of ulcerative colitis with local hydrocortisone hemisuccinate sodium. Ibid., 1, 1437-1443.

- (1958). Treatment of ulcerative colitis with local hydrocortisone hemisuccinate sodium: a report on a controlled therapeutic trial. Ibid., 2, 1072-1077.

- (1960). Systemic and local corticosteroid therapy in ulcerative colitis. Ibid., 1, 464-467.

- Watkinson, G., and Draper, G. (1962). Comparison of corticosteroids and sulphasalazine therapy in ulcerative colitis. Ibid., 2, 1708-1711.

- , and Witts, L. J. (1955). Cortisone in ulcerative colitis: final report on a therapeutic trial. Ibid., 2, 1041-1048.

Watkinson, G. (1958). Treatment of ulcerative colitis with topical hydrocortisone hemisuccinate sodium: a controlled trial employing restricted sequential analysis. Ibid., 2, 1077-1082. 